\title{
Vicky Lofthouse
}

\section{Preparing the way for mainstream sustainable product design}

\author{
Methods and approaches to inspire change
}

\begin{abstract}
This paper proposes that there is a need to prepare undergraduate design students to be responsible practitioners when they enter the workplace. The multi-faceted approach adopted by the Design School at Loughborough University to achieve this is presented. The paper outlines and reflects on the differences between the idealistic environment provided within an educational setting and the actual situation in the design industry, where there is little evidence of mainstream sustainable design practice. The paper concludes that it is valuable to provide students with a range of skills that support sustainable design thinking, even if they are not currently required by the design industry because doing so turns the students into informed individuals with the potential to lead the next generation of design practitioners.
\end{abstract}

Keywords: sustainable design education, design practice, eco-design practice

\section{Introduction}

Designers have an immense influence on the modern world - everything that we interact with, from smart phones to clothing, domestic products, transportation systems and buildings have been intentionally or unintentionally designed. Added to this are the enormous supply chains that can involve hundreds of companies across North America, Europe and Asia (Friedman, 2005) in the manufacturing of a single product; this means that the choices designers make can have positive or negative impacts that ricochet around the world. In 1971, Victor Papanek accused product designers of creating unnecessary products, wastefully propagating product obsolescence and creating 'stuff-lust' that promoted materialistic lifestyles. As material consumption continues to grow, epitomised by marketing tactics such as Black Friday and Cyber Monday (Gittleson, 2013), it is unclear as to whether much has really changed. A more modern voice of the same tone is that of Bruce Nussbaum (2007), who states in his provocative speech at Parsons School of Design that 'designers suck'. He refers to designers' propensity to design 'crap' and their inability to engage with the sustainability debate, among other things, and states that we need to start demanding sustainability in design (Nussbaum, 2007). As such, universities have a moral responsibility to prepare design students to be responsible practitioners when they enter the workplace. At the very least, students should be aware that the decisions they make have consequences. Ideally, however, we should be aspiring to create engaged graduates who are motivated to make a difference, challenge the status quo and be catalysts of change in a move to improve the design industry.

In many ways, the situation in education can be seen as representative of the 'ideal' environment through which to conduct sustainable design projects; students are provided with subject specific training, they have access to hands-on support from experts, sustainable design is a core focus of the brief (and mark criteria), and there is time to complete the work. Additionally as students have elected to take the course, they are typically interested in and motivated by sustainable design. This is very different from the situation in the industry. The present paper focuses on the differences between the sustainable design outputs generated in an idealistic environment provided within an educational setting and the actual situation in the design industry. It draws on the findings of two research studies. Study 1 comprises an 
investigation into the outputs of an elective 'sustainable design' module run by Loughborough University's Design School (LDS). Study 2 reports on a doctoral research study that investigated (among other things) the complexity of addressing responsible design goals within the practice of industrial designer consulting (Stevenson, 2013), which was supervised by the author. Following an overview of the methodology, this paper introduces the sustainable design teaching programme delivered at LDS. It then reflects on the current situation in the industry. The gap between the idealistic environment provided within an educational setting, where constraints are minimal, and the actual situation within industry where there is a plethora of constraints (Stevenson, 2013) is then reflected upon, and lessons are drawn.

\section{Methodology}

Study 1 draws on 12 years' experience of teaching sustainable design to second-year undergraduate industrial and product design students at Loughborough University. The module spans one academic year over two semesters. Semester 1 typically focuses on theory while Semester 2 is practical, providing students with the opportunity to apply the theory to a brief that is set by an industry partner (see below). Each year, the outputs of the projects are collated, and the types of outputs that students generate when provided with theoretical input on sustainable design and a sustainable design brief (set by an industry partner), which is marked against a sustainable design-oriented mark criteria, are reflected on. Data are drawn from a combination of documented projects, observations, informal discussions and workshop interactions. Because of the consistent mark criteria, the theory the students are exposed to and the tutorial input from the staff, many of the elements included in the presentation boards are consistent across different students. This paper draws on a very small selection of presentation boards to illustrate a cross section of designed outputs, demonstrating how the students have translated the taught theory into practice (against the requirements of the module). The sample projects are not intended to represent the best outputs, but rather, they are selected to illustrate specific points. They are, however, representative of the higher quality outputs that have come out of the module.

Study 2 comprises three main data collection phases: a literature review, a workshop and interviews. Phase 1 , an examination of the literature, forms a preliminary construct of the potential key factors influencing the ability of designers to engage in responsible design. This was used to inform the structure of enquiry for the workshop and interviews. Phase 2 consists of multi-disciplinary workshops with 19 participants from design practice and academia in three organised groups, each undertaking a set of individual and group tasks directly addressing the research topic. The activities were audio recorded, and the data collected were analysed to validate the preliminary theories formed from the literature review and provide a pilot data set for the main investigation.

The second phase of Study 2 consists of a series of semi-structured interviews with 31 participants, comprising the following:

- Twenty-two experienced industrial design consultants, of which, 18 were managing directors, directors or sector managers, and four were senior or mid-tier designers from a cross section of prominent firms in the UK and Ireland.

- Four leading academics in the topic area

- Five design-related strategic consultants

Audio recordings from the interviews were transcribed and analysed using coding and clustering methods (Miles \& Huberman, 1994) to map the industrial design's commercial context; identify the range of factors affecting consultants and describe the interrelationships of these elements. 


\section{An Approach to Sustainable Design Education}

LDS takes a multi-faceted approach to the challenge of preparing undergraduate industrial and product design students to be responsible practitioners, incorporating the three pillars of sustainability - environment, society and the economy (Elkington, 1997). Research shows that designers need a combination of information, inspiration, education and guidance to help facilitate their involvement in design for sustainability (Lofthouse, 2001a). The programme delivered at Loughborough was designed to address all these requirements.

Through the 'sustainable design' module, students are introduced to alternate ways of viewing product development through the introduction of concepts such as eco-efficiency, life cycle thinking and systems thinking. They are also introduced to a wide array of approaches, such as design for happiness (Escobar-Tello, 2016), design for behaviour change (Lilley \& Lofthouse, 2009; Lilley, 2009) and social innovation, zero waste and design for the circular economy (Bakker, den Hollander, van Hinte, \& Zijlstra, 2014) to encourage them to think about design differently. The intent is to encourage and enable students to move beyond the lower levels of eco-innovation (e.g. product improvement) illustrated in Figure 1 and to strive toward higher levels of innovation (e.g. function innovation) where greater environmental and social improvement, as well as benefits for the business, can be realised (Bhamra \& Lofthouse, 2007).

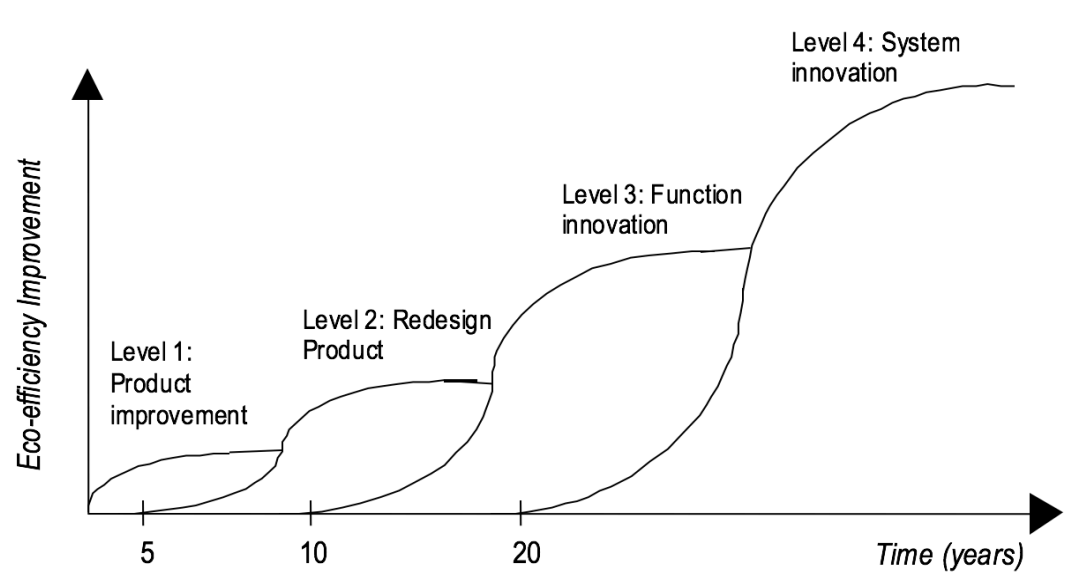

Product improvement: The improvement of existing products with regards to pollution prevention and environmental care. Products are made compliant.

Product redesign: The product concept stays the same, but parts of the product are developed further or replaced by others. Typical aims are increased reuse of spare parts and raw materials, or minimising the energy use at several stages in the product life cycle.

Function innovation: Involves changing the way the function is fulfilled. Examples include a move from paper-based information exchange to e-mail, or private cars to 'call-a-car' systems.

System innovation: New products and services arise requiring changes in the related infrastructure and organisations. A changeover in agriculture to industry-based food production, or changes in organisation, transportation and labour based on information technology.

Figure 1: Four-stage model of eco-innovation (Brezet, 1997). 


\section{Illustrative Case Studies}

Case studies are frequently embedded in lecture material and provided via the virtual learning environment. They have proven to be an effective way of inspiring students' creativity and illustrating how environmental improvements and societal issues have been addressed by different designers and organisations. For example, 'BABYBE' is used to demonstrate the positive impact that well-considered design can have on people's lives (The Creators Project, 2013). 'BABYBE' is a bionic mattress that keeps mothers and their babies 'physically' connected while the baby is in an incubation unit within a neonatal intensive-care unit. Through a range of sensors, it transmits haptic information from the mother to the baby in real time to help maintain a physical bond between mother and child (The Creators Project, 2013).

The Philips' SenseoUp ${ }^{\circledR}$ one-cup coffee machine (Figure 2) demonstrates the holistic and methodical approach that Philips takes with eco-design. It illustrates the ways in which the designers have responded to the different focal issues that Philips identified as important - energy, packaging, substances, weight and materials, circularity and lifetime (Koninklijke Philips Electronics N.V., 2016). A smart interface means that the machine warms up, brews the coffee and shuts down with one touch of a button. By switching off immediately after the coffee has been brewed, a $10 \%$ energy savings is achieved compared to previous products. Its smaller size means that it needs less packaging and causes fewer emissions during transport (Philips Design, 2015). This product also improves on previous generations of coffee machines by utilising $13 \%$ recycled plastics. The considerable technical challenges required to achieve this relatively low percentage of recycled materials provide useful and realistic insights for students.

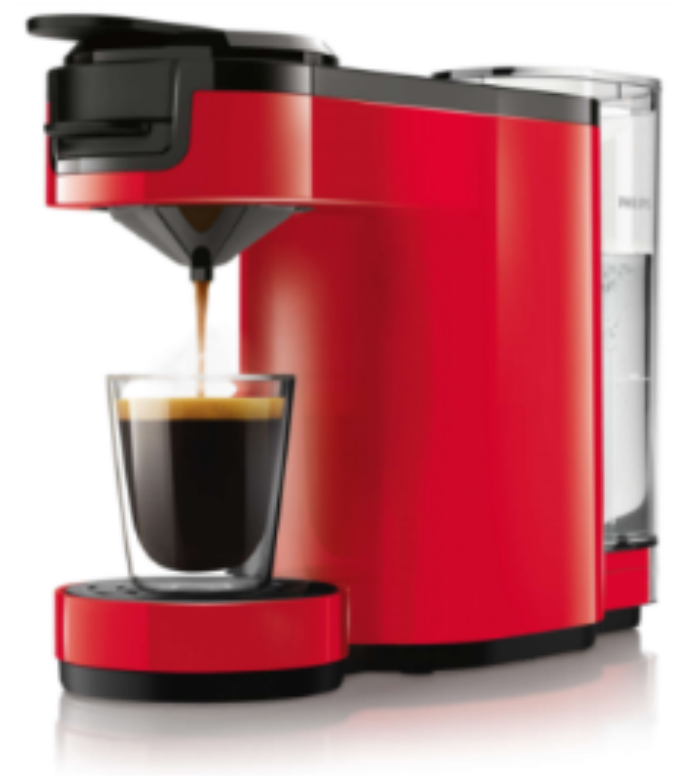

Figure 2: SenseoUp® one-cup coffee machine, Philips Design, 2015.

A third example is the award-winning $\mathrm{Mu}$ folding plug (Made in Mind, 2015), which dramatically reduces the weight and volume size of the bulky British power plug. This innovative product design leads to great reductions in the carbon footprint of products shipped with this design because smaller pack sizes can be used. If it were rolled out internationally, it could lead to enormous reductions in carbon emissions. 


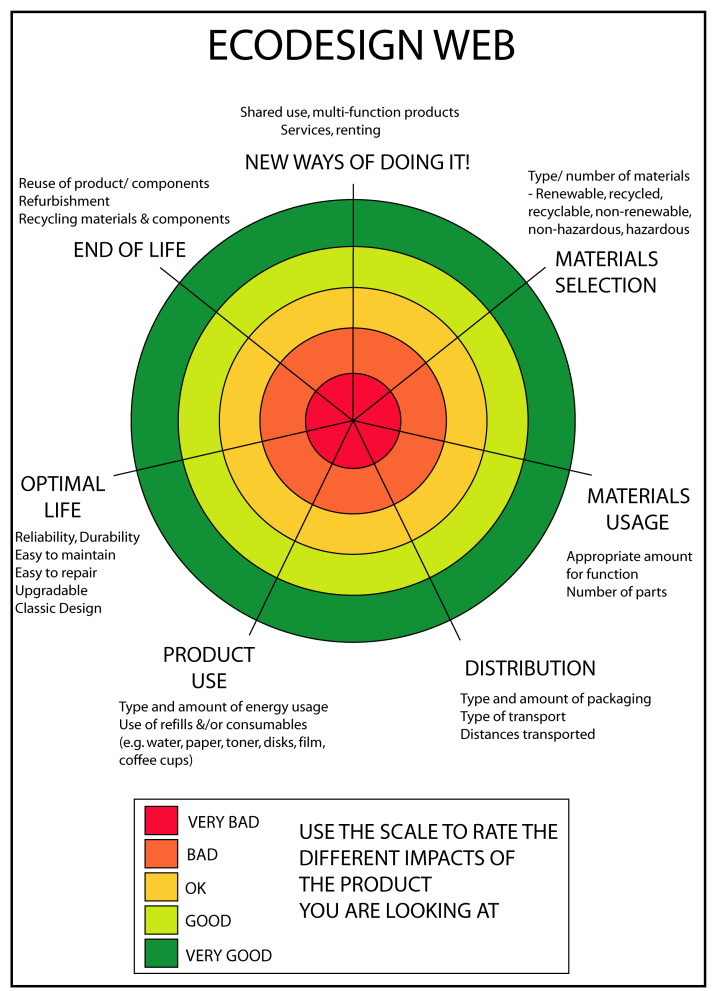

Figure 3: Ecodesign Web (Lofthouse \& Bhamra, 2000).

\section{Tools}

Via a series of two hour workshops across Semester 1, the students are introduced to a range of quantitative and qualitative tools, including the Ecodesign web (Lofthouse \& Bhamra, 2000), EcoIndicator 99 (PRé Consultants, 1999), CES EduPack (University of Cambridge, 2008), Abridged Design Abacus (Bhamra \& Lofthouse, 2007), Social Issues cards (Lofthouse, 2013) and Dirty Carbon (Lofthouse, Manley, \& Shayler, 2015):

- Ecodesign web is a quick and easy tool that helps designers qualitatively assess a product or design to identify the key areas the designers need to focus on. It works by comparing the seven design areas (see Figure 3) to identify a 'better than' and 'worse than' output. When the activity is complete, the shape created illustrates which areas need the most attention. Having carried out the Ecodesign web analysis, designers should focus on improving the highlighted areas.

- EcoIndicator 99, developed by PRé Consultants B.V. (www.pre.nl) is an abridged life cycle analysis tool that quantitatively assesses the impact of a product or system using over 200 pre-defined 'eco-indicator values' for common materials and processes. It provides a quick assessment of a product or system with respect to the impact on damage to human health, damage to ecosystem quality and damage to resources in millipoints (mpts). It is a direct competitor of the carbon footprinting approach and provides a much more comprehensive review of environmental impact.

- CES EduPack $\subset$ is a tool created by Granta Design Limited in Cambridge and is used predominantly for material sciences. The tool is split into a variety of database levels that allow access to a variety of material types and associated manufacturing processes. It also allows levels of complexity (from introductory to advanced) to be chosen for a particular field of enquiry, such as eco-design, architecture, bio-engineering and aerospace. The tool also offers additional teaching and student resources within each database level. 
- The Abridged Design Abacus is a qualitative tool that helps designers assess the sustainability performance of a product, highlight the areas where further research is needed and outline the targets for their redesign. It can be used to analyse the performance of an existing product, compare a number of alternative design solutions and make detailed comparisons against other designs. The Design Abacus can be used to evaluate a product against specific criteria under a range of focal areas: lifecycle (manufacture, use, end of life, packaging); social (need, social enrichment) and other (cost, quality, aesthetics).

- The Social Issues cards are a set of 31 handheld cards created to help designers consider relevant social issues in their design work. The cards combine a series of relevant questions and illustrative case studies to demonstrate how others have addressed the question posed. They can be used as a stand-alone tool by individuals or groups of designers or be used in conjunction with tools such as the Design Abacus to encourage the consideration of social issues alongside environmental ones.

- Dirty Carbon is a bespoke in-house tool developed specifically to introduce design students to carbon foot printing.

In each case they are introduced to the tool and then engaged in a hands-on workshop in which they use the tool to assess a given product. The tools that are taught are intended to cover a range of different requirements, allowing students to assess the environmental impact of existing products and services to identify strategic areas for improvement, consider social issues that may be relevant and measure any improvements made (to name but a few).

\section{Working with Industrial Partners}

To support practice-based learning in the second semester, the students undertake a sustainable design project set by an industrial sponsor (in the past, this has included Hoselock, PDD, Philips and Graphic Packaging International [GPI]), which enabled them to put theory into practice. They were supported by weekly group tutorials with a staff member. This provided them with a safe environment to 'have a go' at sustainable design and experience the challenges of managing a range of competing requirements (styling, manufacture, environmental stewardship and social justice).

\section{Approaches and Outputs From Sample Student Projects}

This section will draw on several student projects to introduce the types of briefs addressed, illustrate the types of outputs generated and reflect on the types of issues taken into consideration as a result of the knowledge and guidance provided through the programme.

First is a student's response to a brief set by GPI in 2015 to 'redesign a piece of supermarket fruit or vegetable packaging so that it incorporates carton board, helps reduce waste and assists with food portioning'. The pack is designed to supply one portion of blueberries and one portion of raspberries to be used as snack packs. In this example, the student takes an eco-design approach (Eco2-irn, 1994), focusing on reducing the environmental impact of the fruit packaging through the application of five of thestrategies which make up the Ecodesign Web - materials selection, materials usage, distribution, optimal life and 'new ways of doing it'. Figure 4 illustrates the student's output in response to the brief through the use of medium fidelity prototyping and CAD storyboarding. The student reflects:

Overall... the packaging [is]... greatly improved compared to the original PET packaging, as shown in the web diagram, the only weak points are distribution and optimal life... It is overall more sustainable than the PET packaging and meets all the required legislation. By 
being portioned correctly, it reduces waste and influences people to consume at least one to two of their five a day by eating the contents of the package, by knowing it is one of their five a day they are more likely to consume the whole box (reducing leftover waste).

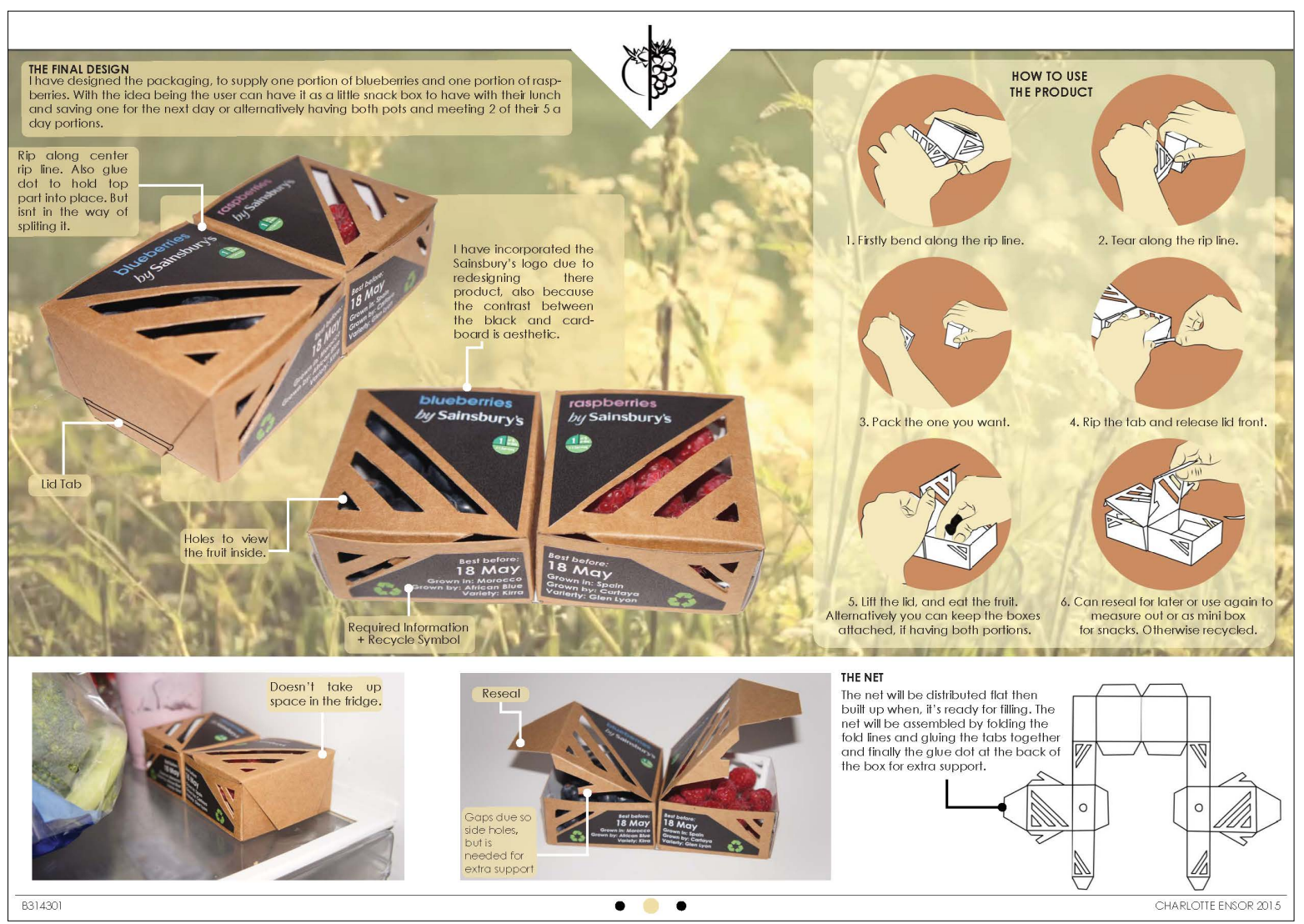

Figure 4: Fruit packaging concept by Charlotte Ensor, 2015.

Using the tools and knowledge gained, the student is able to reflect on the improvements made, identify shortcomings in the design and pull out key messages that can be communicated to the client. Figure 5 illustrates how she used the Ecodesign web to organise her thinking and reflect on the improvements that were made to the packaging against the eco-design strategies that she identified as relevant to the brief.

A different take on the same brief is illustrated in Figures 6 and 7. This student's proposition uses the sustainable design remit, considering a range of social and environmental issues (Eco2-irn, 1994). Along with reducing types of materials, materials use and recyclability were designed to encourage sharing and social interaction. The student also incorporated a $\mathrm{QR}$ code with links to recipes for damaged or spoilt fruit to further reduce food waste, a big issue in the UK (WRAP, 2015). Again, Ecodesign web is used to help communicate some of the benefits of the packaging proposition. This example also demonstrates another key requirement of the project (part of the marking criteria): to consider the limitations of the proposition. This requirement encouraged students to critically reflect on their ideas to increase their learning (Schon, 1990). 


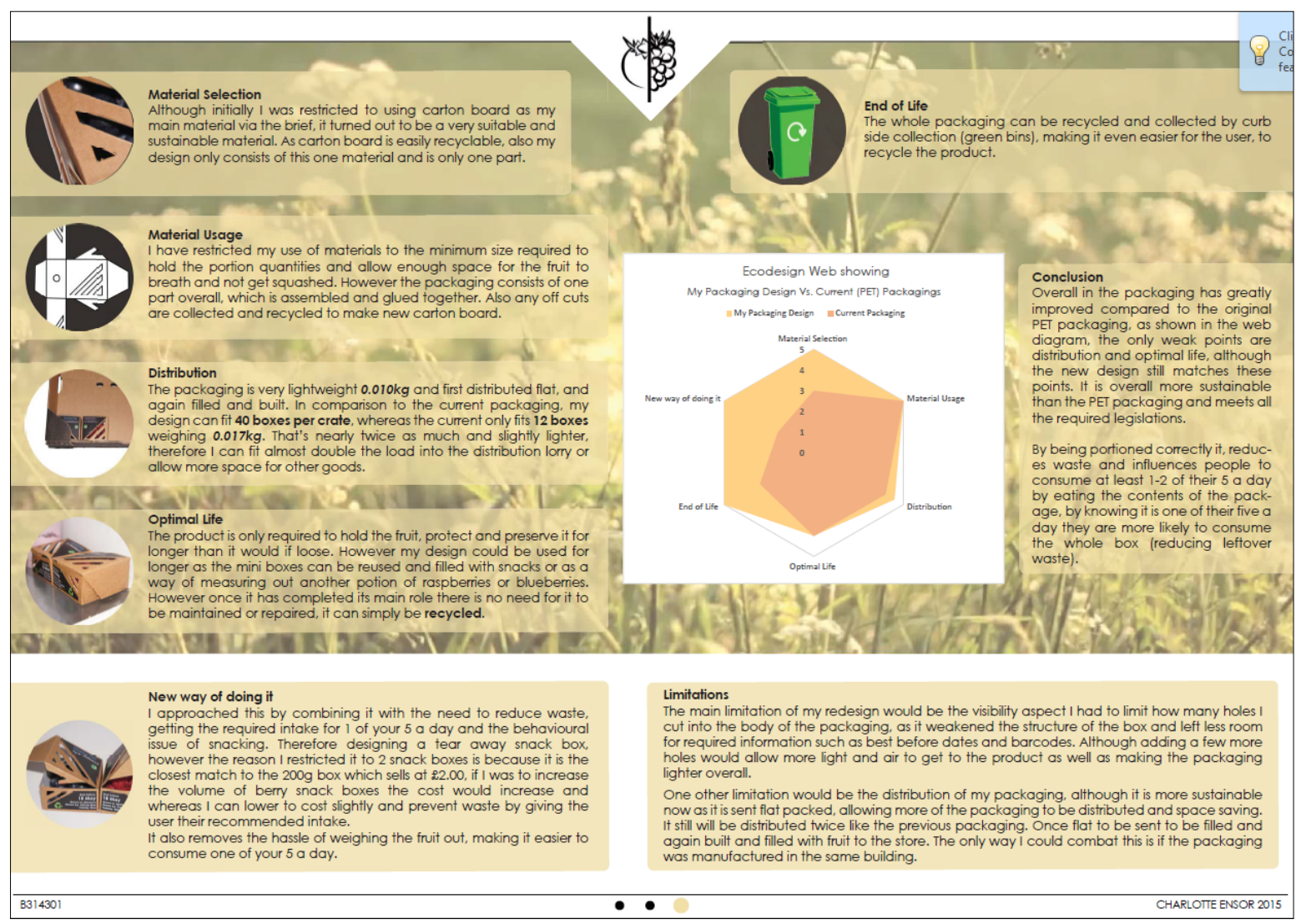

Figure 5: Product improvements and limitations by Charlotte Ensor, 2015.

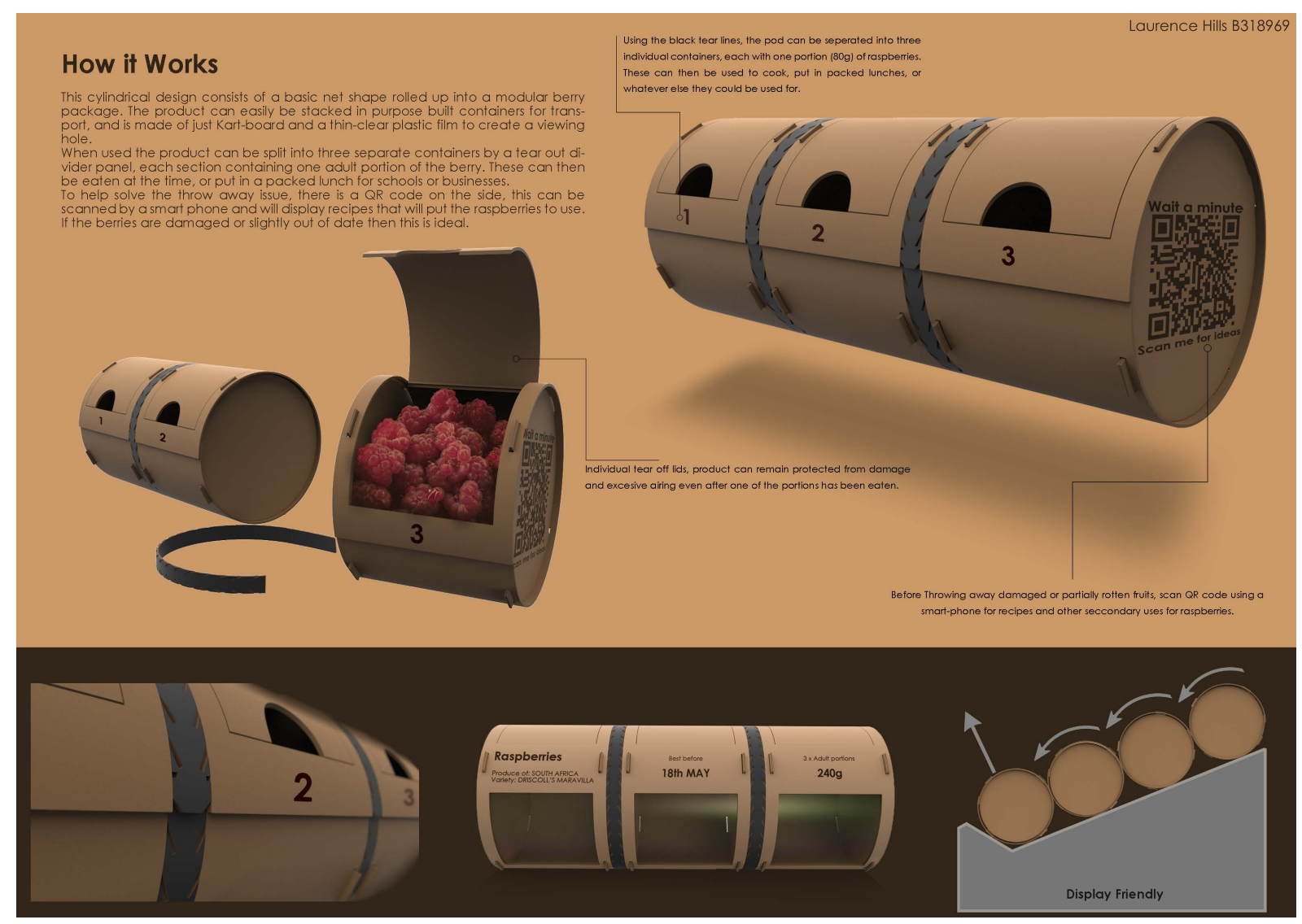

Figure 6: Design proposition for berry packaging by Lawrence Hills, 2015. 


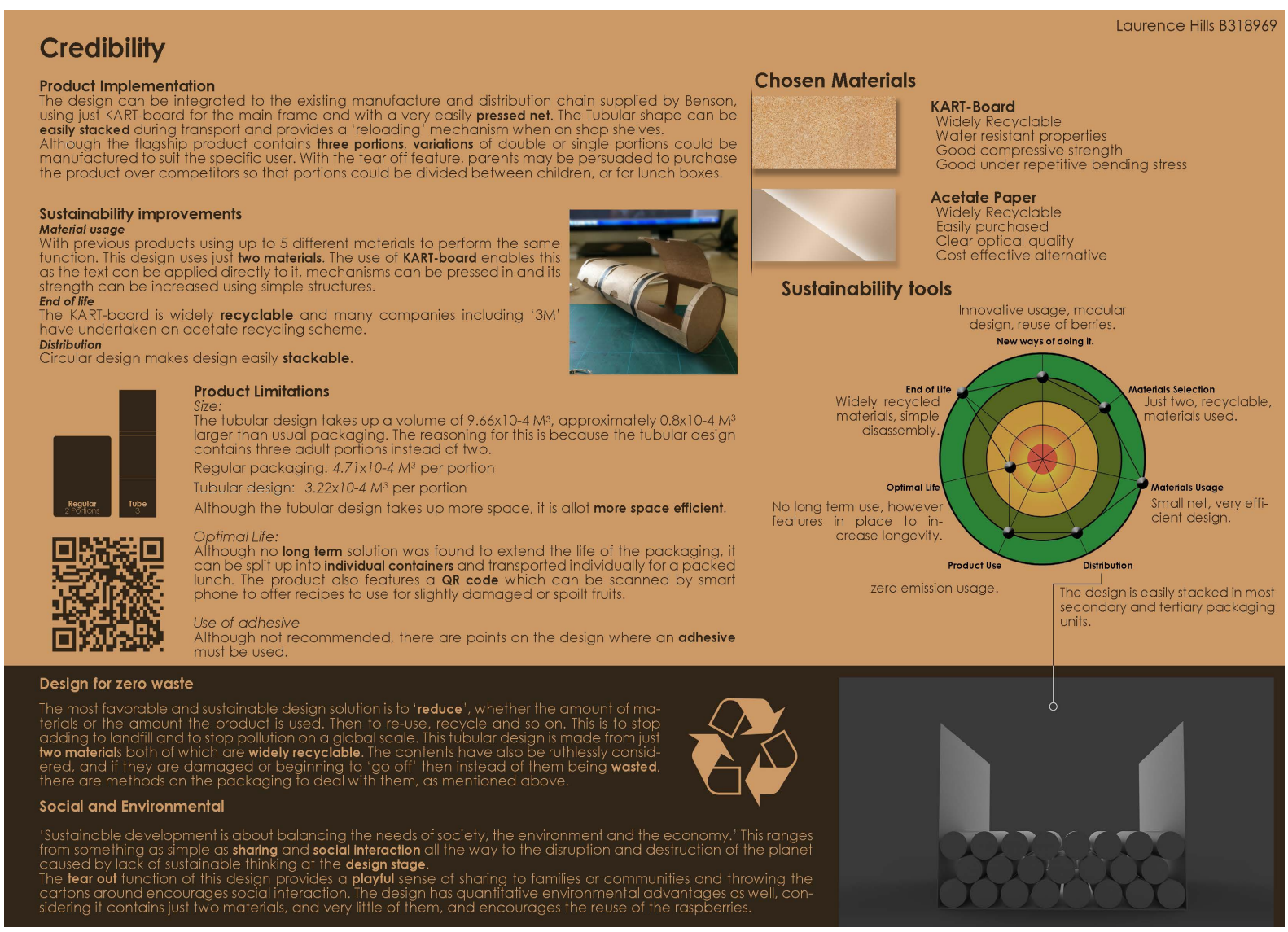

Figure 7: Product improvements and limitations by Lawrence Hills, 2015.

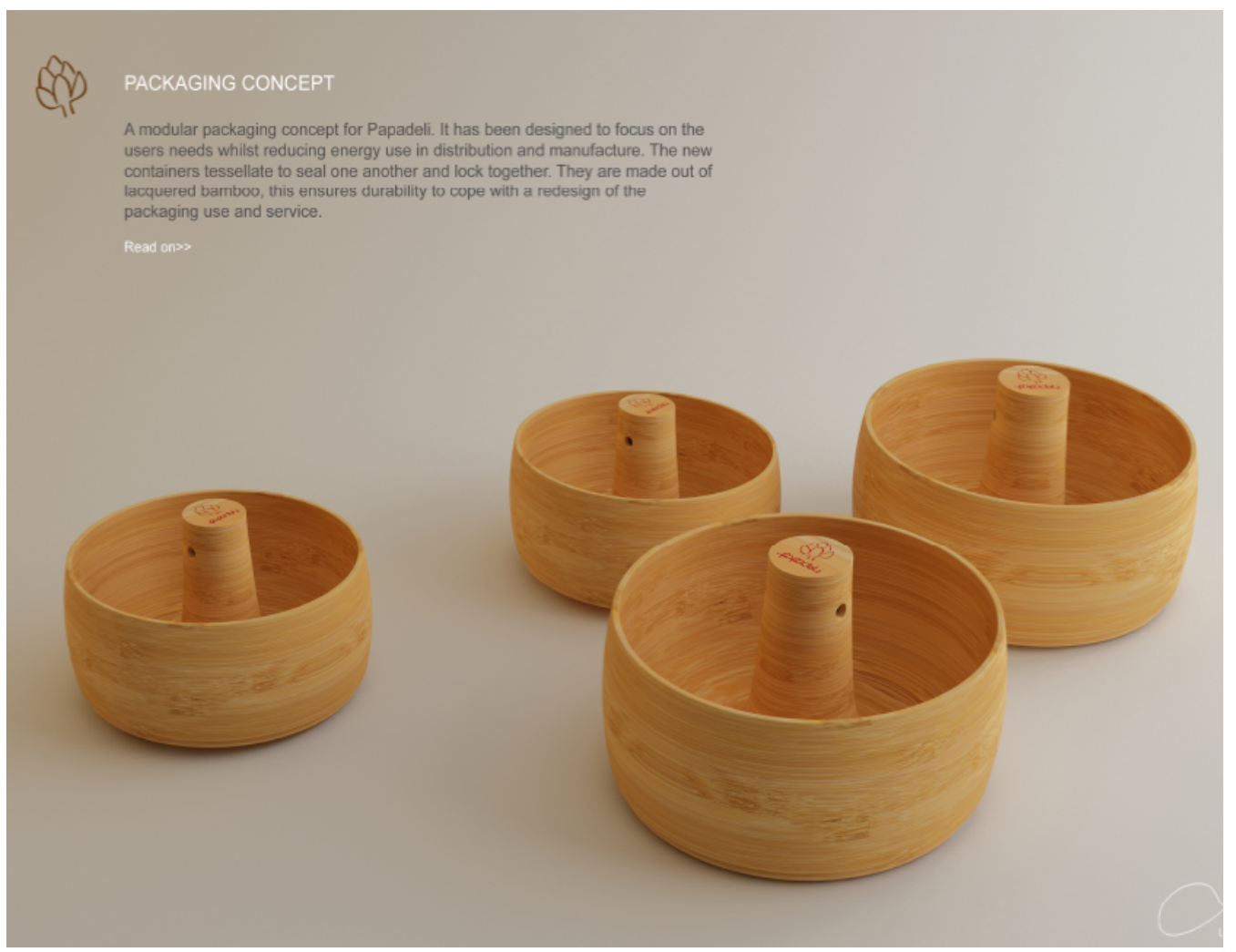

Q THE SERVICE

Alongside the physical packaging redesigna new jeveloped to further addre: the susti nat

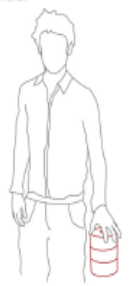

Based on a closed loop jystem, the packaging is eussed and is returned by thiy egularity and security of the (cistomers, a return scheme ss easible. The packaging is back each time to to be exchanged for clean ones ân new food

This service decreases input of excess material, reduces shipping quantity, allows fo specialised recycling and gives the brand a stronger dentity.

This service has been analyzed based on a typica 20-25 trip time for the packaging.

Figure 8: Design proposition for reusable deli packaging by Laurie Howell, 2008. 
The student project illustrated in Figure 8 is a response to a brief set by the PDD in 2008 to investigate 'luxury in sustainable packaging'. The student used a combination of Ecoindicator 99 (PRé Consultants, 2000), brand analysis and consumer questionnaires to investigate the impact of the take-away containers used by Papadeli. He chose to focus on extending the life of the existing disposable packaging. Modular packaging created out of lacquered bamboo was combined with a service concept to increase the customer experience, enhance customer buy-in and support the Papadeli brand. The student quantified his improvements using Eco-indicator 99 (PRé Consultants, 2000). This proposal is also a good example of a design proposition that incorporates a service element to enhance its sustainability credentials. In this case, a closed-loop system is adopted, whereby the user brings back the packaging to the deli to have it refilled. The 'high-end' focus of this proposal and the local nature of the deli means this approach is well-suited to the student's persona a time-poor, money-rich Londoner who commutes to work on a daily basis and wishes to eat fresh food for lunch. It is worth noting here that the approach taken by this student is very much in line with the approach that a sustainable design consultant would take because it uses an environmental analysis, consumer research, ideation, a presentation of a proposition and an assessment of environmental improvements.

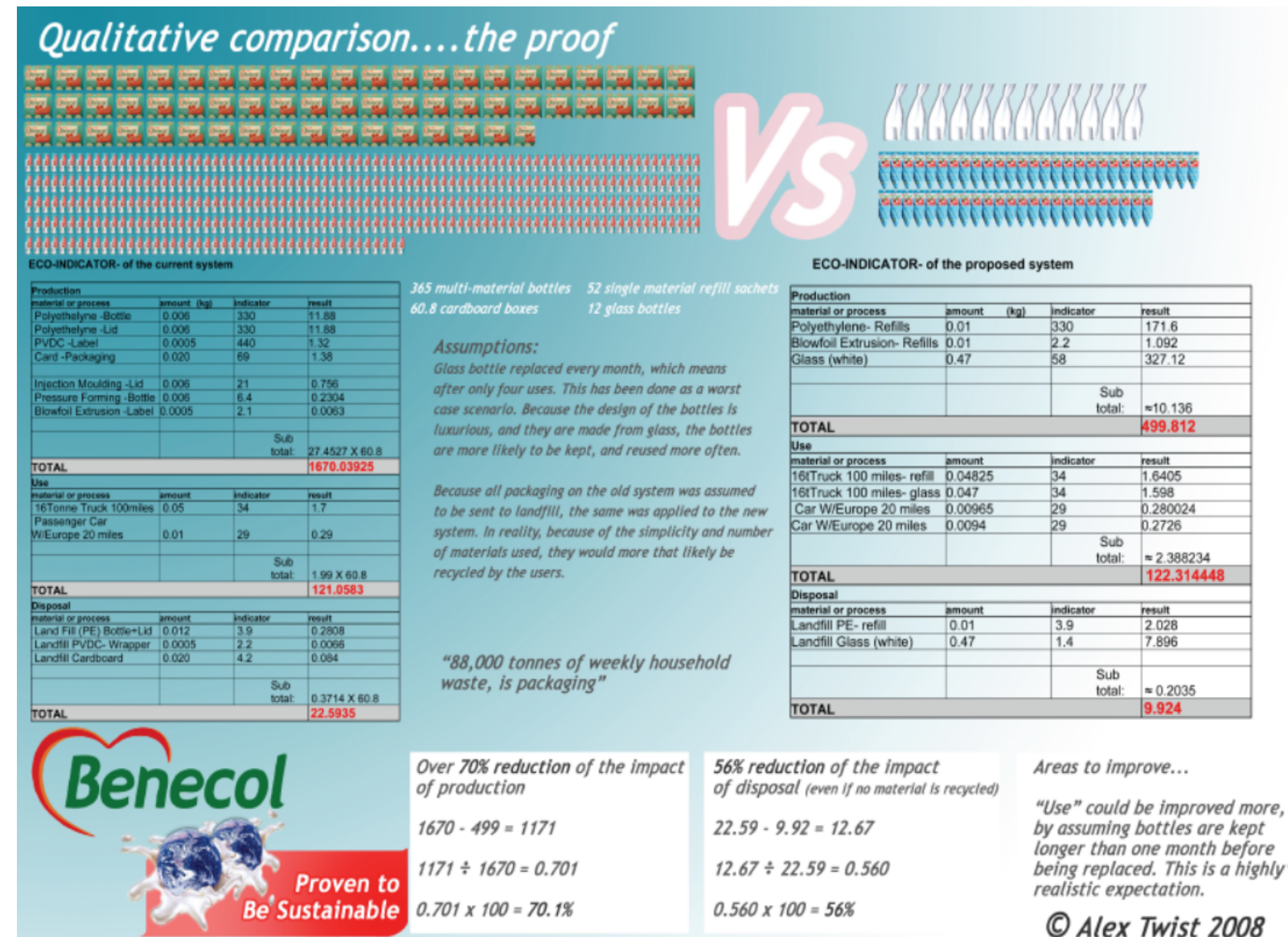

Figure 9: Environment analysis to demonstrate reduced impact of using weekly refill sachets and a glass bottle against single-serving daily PET bottles by Alex Twist, 2008.

Figure 9 is another response to the same brief. In this example, the student used Ecodesign web and a consumer questionnaire to direct his redevelopment of the daily Benecol yoghurt bottles into light weight weekly sachets that can be poured into an attractive decanter. The 
final concept not only improved the environmental impact, but also the consumer experience. The student then went on to use Eco-indicator 99 to demonstrate the level of environmental improvement that had been achieved in terms of production, distribution and disposal.

Both solutions for the PDD brief demonstrate the importance put on the need to carefully consider the users and their requirements, desires and aspirations, not just the environmental credentials. They also both illustrate the value of eco-design tools in identifying appropriate areas to focus on within the product development process and how being able to quantify improvements can be a useful communication aid when reporting back to the client.

The project illustrated in Figure 10 is a response to a brief set by Ticketyboo in 2013 to look for opportunities for 'solar fridge use in developing countries'. It is an example of one of a few overtly socially oriented briefs that students have been offered over the years. The project in Figure 10 features a water-filled backpack that is cooled using solar energy. Though there are a number of ways in which this could have been developed further, it is illustrative of the types of projects that the students undertake and the degree to which they develop them within the 11 weeks available.

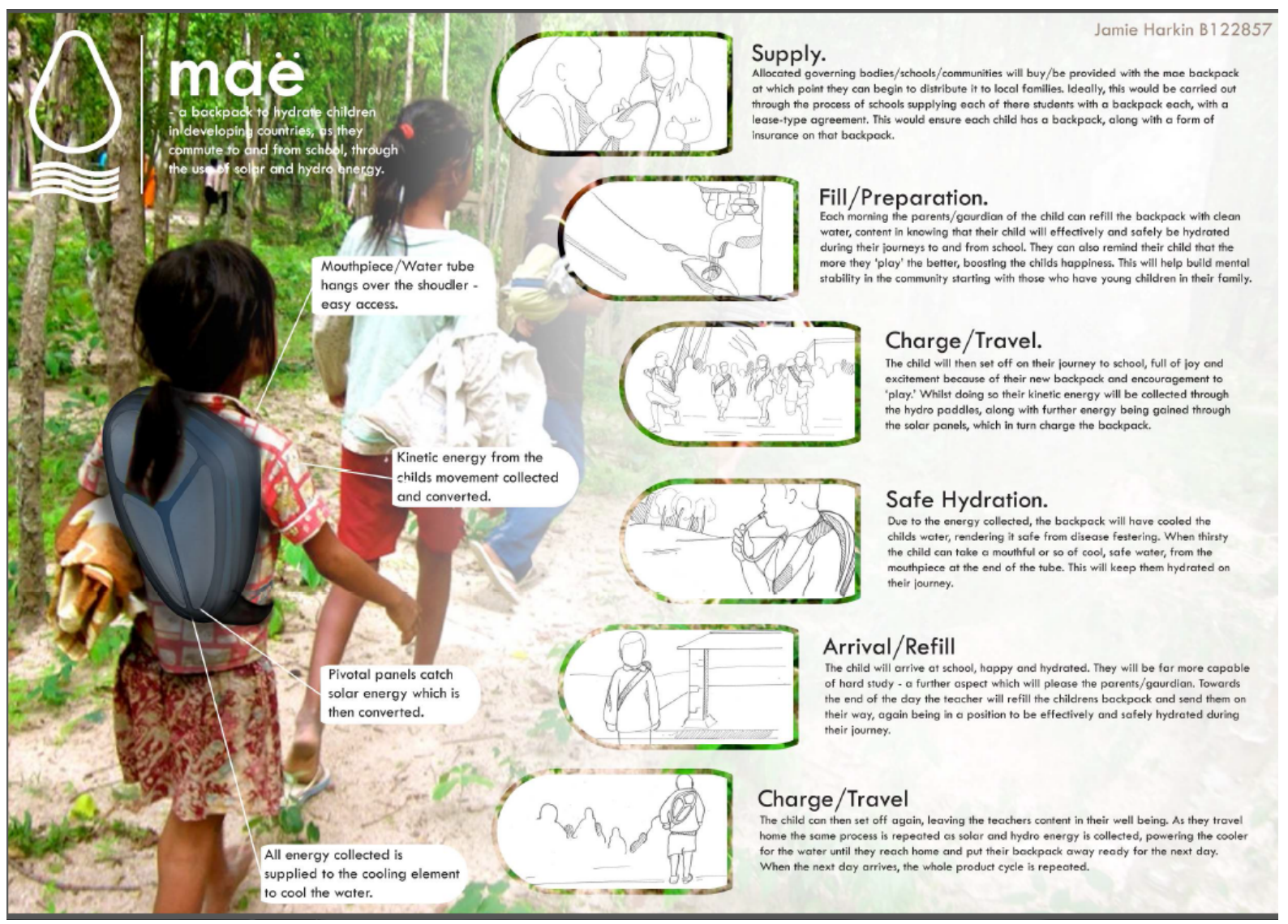

Figure 10: Hydrating solar backpack for school children by Jamie Harkin, 2013.

The final example is a response to a brief set by Boots in 2013, which asked students to 'select a beauty or personal care product and design the packaging to have a useful after life'. Here, the student designed a refillable body spray package for extended product life. In this case, we were able to provide access to recent associated research carried out within LDS (Lofthouse, 2007; Lofthouse, Trimingham \& Bhamra, 2009). This example (Figure 11) also helps to demonstrate that the students are encouraged to treat this as a design project and draw 
on all the skills that they would use in other projects, such as aesthetics, ergonomics, user requirements and technical suitability. The aim in the module is to challenge students to respond to the brief as they would if working in the industry, helping bridge the gap between theory and practice.

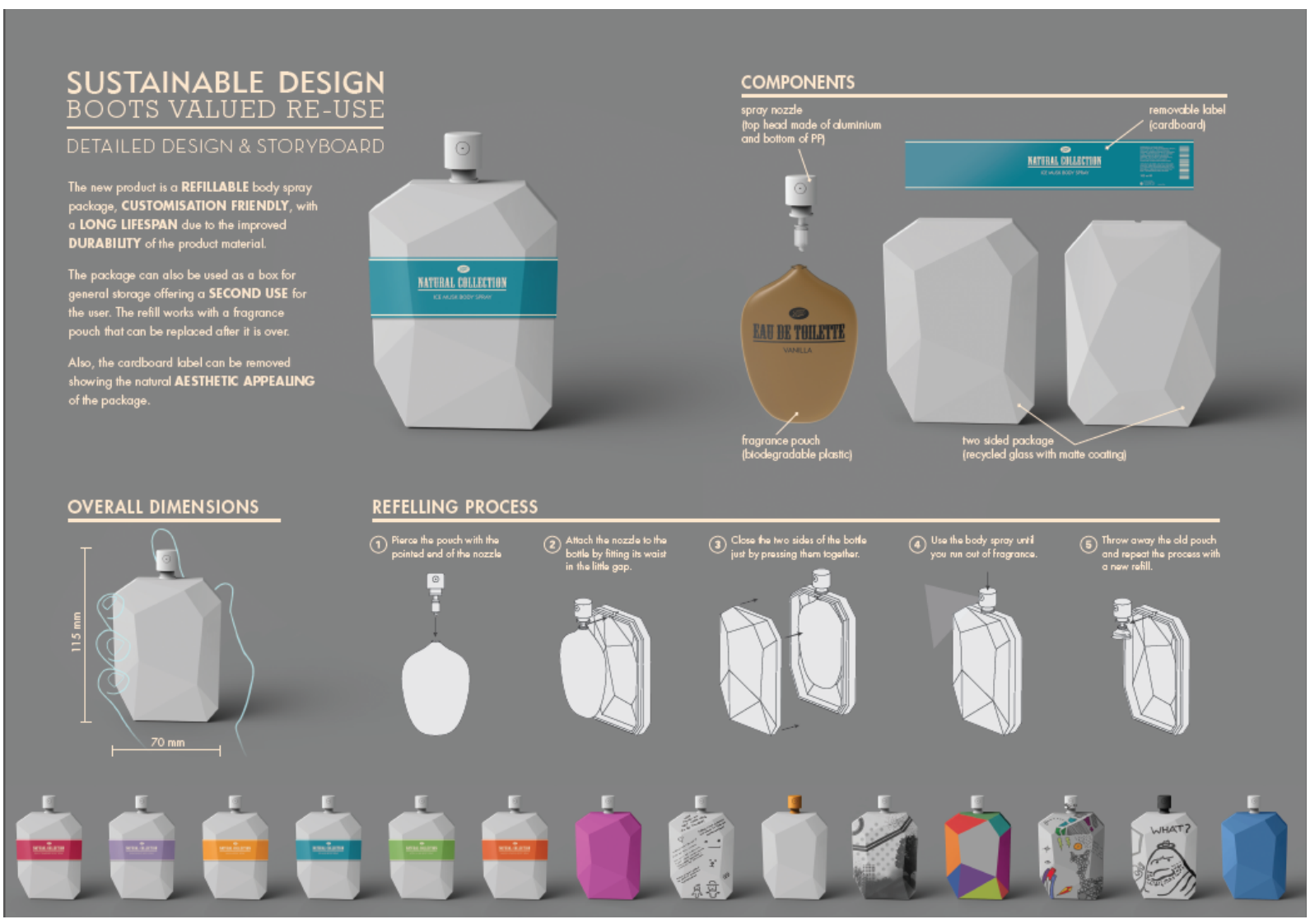

Figure 11: Refillable perfume packaging by Anderson Koyama, 2013.

Over the years, projects have been set by a wide range of companies, some that already recognise and respond to sustainability challenges as a core part of their business, and others for whom this is a new consideration. From a classroom perspective, working on an industrial brief is an effective way of introducing students to 'real-life issues' such as material costs, marketability, shelf impact and how products are transported, which they might easily ignore without partnering with an industry client. From the client's perspective, they benefit from the generation of a number of different ways to think about the environmental and social performance of their products, typically achieving higher levels of eco-innovation (Levels 2-3 of Brezet's model in Figure 1) than would be expected in a commercial context.

The approach taken at the Loughborough Design School has shown to produce wellinformed graduates with a good understanding of the issues that are relevant to designers; the approach also provides students with a suite of tools and methods that they can draw on to help them create more responsible products, services and systems. This is born out of informal feedback from employers through the projects undertaken in the final year of their degree. Additionally, every year, undergraduate designers from Loughborough University specifically seek out sustainable design-related placement and employment opportunities, which is a testament to their interest and engagement in the subject. 


\section{Current Practice in the Design Industry}

Examples of good sustainable design practice can be found in a wide range of sectors across a variety of different organisations, and though these examples are important and of great value, they are not evidence of widespread practice. Multinationals such as Herman Miller, Philips and Boots have been recognised for their good practice in the area of eco-design and sustainable design over a number of years (Gander, 2007; Herman Miller, 2005; Koninklijke Philips Electronics N.V., 2002; Lofthouse, 2001b). In these organisations, although their sole purpose is not sustainability, there is compelling evidence of understanding sustainability and programmes to facilitate practical application. Typically, large enterprises take a life cycle approach to sustainability to identify the key environmental impacts across the product's life cycle (materials extraction to end-of-life considerations and everything in between). They use this analysis to strategically focus on systematic reduction (Sherwin, 2004), as illustrated by the SenseoUp® one-cup coffee machine (Philips Design, 2015). They tend to focus on "organising and optimising the hard, "material" parts of the product - to make it easier and cheaper to make, to improve the quality and ... lower the environmental impact' (Sherwin, 2004: 23). As such, development is typically incremental, in which a series of small changes are made over time, typically equating to Levels 1-2 on Brezet's model (1997), illustrated in Figure 1.

Other, more dramatic, examples tend to emerge from the industry as a result of research collaborations with universities and in programmes outside of a company's day-today product development practices. This sort of space provides the time for detailed supporting research, ethnographic investigations and user testing of futuristic concepts. An interesting example is the Closed Loop Emotionally Valuable E-waste Recovery (CLEVER) project set up to solve the issue of recovering waste from small electronic devices such as mobile phones. CLEVER's approach involves developing a product service system based on a durable exterior that 'ages gracefully' and circuit boards that can be dissolved to easily recover valuable metals and keep them in the manufacturing loop (Wilson et al., 2015). This research project achieves Level 3 eco-innovation, moving toward Level 4 if taking into consideration that it plans to change the way that circuit boards are manufactured and reclaimed at the end of the product's life.

\section{Little Evidence of Change in Design Practice}

Despite the examples presented above and a growing body of research interested in engaging designers in sustainability (Brezet, 1997; Lofthouse, 2006; Lofthouse, 2004; Simon et al., 1998), there is little evidence of any great sea change across the design industry (Sherwin, 2012; Short, Lee-Mortimer, Luttropp, \& Johansson, 2012; Stevenson, 2013). Although there is often an appetite for sustainable design thinking among individual designers, the opportunity to actively engage with the issue is often not there. Recent literature has helped to build a profile of the challenges that face designers when it comes to engaging with sustainable design; these will be reflected on below.

To engage in sustainable design practice, designers need to know how to effectively address the arising issues such as making comparative analyses between different strategic options. Research has highlighted barriers related to the availability of suitable information, the clarity and usefulness of that information and, importantly, the designer's confidence in it (Lofthouse, 2001a; Stevenson, 2013). Even those who are keen to engage in these issues are often unsure as to where best to start and how to be the most effective (Stevenson, Lilley, Lofthouse, \& Cheyne, 2011). A commonly held opinion is that many of the issues have only been highlighted relatively recently and are open to interpretation (Stevenson, 2013). Often, product designers find it difficult to evaluate the impact of both the positive and negative consequences of their decisions and hence lack confidence in identifying 'what is better'. 
Empirical research indicates that the absence of a consistent methods of assessment means that designers are not confident that whatever they propose will be an improvement on the baseline product (Lofthouse \& Stevenson, 2013), despite the fact that design students consistently use qualitative and quantitative tools to assess the environmental improvement of a redesigned product.

Although there are numerous eco-design tools available (see, Bhamra \& Lofthouse, 2007 ) to help with this process, there is no evidence of any widespread uptake of the tools of by designers either in the literature (Lofthouse, 2004; Perez, 2016; Stevenson, 2013) or through ongoing collaborations with UK design companies. Informal observations during consultancy activity have shown that if designers take the time to use the tools available, they can be very helpful in guiding the process of considering eco- and social issues; however, a lack of internal knowledge and confidence means that they are not utilised when perhaps they could be.

A survey by the Design Council in the UK identified that only $15 \%$ of design businesses feel they are very well-equipped to advise their clients on sustainable design issues (Design Council, 2010). This lack of confidence in their ability to address sustainable design issues has repercussions when it comes to developing appropriate briefs and challenging the client's constraints and assumptions. Having the confidence and ability to do this for a sustainability brief depends on the skills, abilities and knowledge of the designer and is formed by the designer's education, training and experience (Stevenson, 2013). If this knowledge has not been gained at university, there are few options available through ongoing professional development.

Designers are also limited by the opportunities available to them at various fronts, such as the characteristics of the client, the project and the product and where in the product development process they are involved (and for how long) (Stevenson et al., 2011). Opportunities are also limited by project constraints such as time to market, the product's price point, manufacturing lines, distribution channels and legislative requirements (Stevenson et al., 2011). These are compounded by the challenges inherent to design work, such as demanding workloads and tight timescales, which means there is seldom time to fully reflect on issues such as sustainability (Stevenson et al., 2011). Whether more sustainable solutions make it to the market ultimately depends on what is implemented. Proposals focused on sustainability can be dropped at any of the decision gates - internally by the designer or externally by the client (Stevenson et al., 2011).

\section{Discussion: Reflecting on the Gap Between Theory and Reality}

The present paper proposes that there is a considerable difference between the levels of ecodesign innovation (Brezet, 1997) being achieved by the student projects at LDS, which tend to be more radical (Levels 2-3), and industry outputs, which tend to be incremental (Levels $1-2)$. This is because student work is carried out in an 'ideal' environment that lacks many of the constraints that hamper professional designers' efforts to engage in more responsible design. As outlined above, the programme delivered through LDS incorporates training on pertinent issues, case studies to demonstrate how others have done it, on-going hands-on support from experts, a sustainable design-focused brief (and mark criteria), time to complete the work and the fact that students are typically interested in and motivated by sustainable design. The implication being that if the students' experiences can be replicated (even in part), there will be greater opportunities for success within the professional arena.

An observed side effect of this disconnect between theory and practice is that motivated students become disillusioned when they look for work in the area of sustainable design because they become aware of the limited options within the industry, where sustainable design practice is typically of minimal importance for most of the design industry. 
However, it is important to be able to guide enthusiastic students who wish to pursue their sustainability interests while on placement or once they leave university. This can be done by suggesting they target companies with active environmental affairs or corporate social responsibility departments and by ensuring that they make their interests (and skills) known. On a number of occasions, it has been observed that students who have expressed interest and knowledge in this area have found themselves in charge of developing sustainability-oriented projects for their placement companies.

The findings reported in this paper demonstrate that there is also a disconnect between the level of importance given to the topic of sustainable design within design education and that given to it in industrial practice. Based on the relatively low level of engagement within the industry (Sherwin, 2012; Short et al., 2012; Stevenson, 2013), one might question why so much effort is put into educating future generations of designers about these issues when time might be better spent focusing solely on the skills that the design industry currently utilise. However, to move beyond the status quo, there is a real need to equip product designers with the knowledge, skills, interest, support and environment to create socially and environmentally responsible products, services and systems as part of their mainstream work. To do this, education is critical.

Empirical research from numerous sources shows that designers typically do not use eco-design tools and methods for a variety of different reasons (Lofthouse, 2006; Luttropp \& Lagerstedt, 2006; Macdonald-Smith \& Short, 2007; Short et al., 2012). Despite this lack of uptake of eco-design tools, in the Design School at Loughborough University, they are still considered to be an important component of a well-rounded sustainable design education. Though, in the industry, there are many issues that determine the likelihood of designers to have the opportunity to engage in more responsible design (Stevenson et al., 2011) such as time challenges and a lack of demand from clients, this paper argues that a key barrier is a lack of confidence because of a lack of education and practice. This is supported by empirical evidence collected during a number of consultancy commissions, where the author introduced designers and design teams to a number of the tools used with the students, and these tools were well-received. Introducing student designers to tools of this nature while they are still in school will go some way toward improving this situation in the future.

Many of the tools that the students are introduced to provide a structure through which they can think about eco-design and sustainable design issues. By using them as a brainstorming tool, they can be a useful way of guiding the consideration of environmental and social issues across the product life cycle. Often they also useful as a mechanism by which design teams can communicate proposed product improvements to a client or interested party, as illustrated in Figure 5 (by demonstrating that different areas have been taken into consideration). The ability to do this confidently is clearly missing in current design practice. By providing students with practical tools, they will be equipped with skills that are not widely held in current industrial design practice, increasing their value as graduates. For example, carbon footprinting is now widely used as an indicator of sustainability within the industry (Cholette \& Roeder, 2012; Humphries-smith, 2007). The hands-on experience students have of using carbon footprinting tools at school is likely to increase graduates' confidence if they are required to do so professionally. The inference being that if practicing designers could be provided with 'on-the-job' training in this field, there is a good chance that the consideration of sustainable design issues in practice would go up.

\section{Conclusions}

This paper has considered the gap that exists between the theory taught in universities to undergraduate design students and the reality of the design industry when it comes to sustainable design. It has presented an argument that there is real value in providing design 
students with a range of skills that may not be currently required by the design industry. The Red Dott (international design) awards already recognise the importance of environmental criteria, such as durability and ecological compatibility (associated with materials and manufacturing intensity, energy consumption, disposal and recycling) and social issues (such as emotional attachment and product longevity) as positive criteria (Red Dott Award: Product, 2015). It is positive to see these criteria making up a third of the overall criteria, alongside degree of innovation, functionality, formal quality, ergonomics, product periphery and selfexplanatory quality (Red Dott Award: Product, 2015). By equipping graduates with the knowledge and skills to enable them to challenge decisions regarding the environmental and social performances of the products that they create, they leave university as informed individuals with the potential to lead the next generation of design practitioners.

One could argue that continuous education is also critical. Currently, designers who have not been trained in sustainability have little opportunity, beyond conference and workshop attendance, to engage in professional development that focuses sustainable design issues. They need to be trained holistically so that they are aware of the many facets and approaches that can be utilised under the banner of sustainable design while also developing the confidence to utilise and apply them. There is plenty of expertise within universities to provide this. This would also create opportunities for well-informed graduates and ensure that their enthusiasm is capitalised on.

\footnotetext{
Acknowledgements

Special thanks to Dr Debra Lilley, Dr Rhoda Trimingham, Professor Bhamra and Dr Carolina Escobar Tello, who have, at varying points over the last 12 years, contributed to a greater or lesser extent to the delivery of content on the second-year elective module to which I refer in this paper. Also to Norman Stevenson whose work I draw heavily from in reference.
}

\section{Dr Vicky Lofthouse}

Senior Lecturer in Industrial Design

Loughborough University, Design School

Email address: v.a.lofthouse@lboro.ac.uk 


\section{References}

Bakker, C., den Hollander, M., van Hinte, E., \& Zijlstra, Y. (2014). Products that last product design for circular business models. Delft, The Netherlands: TU Delft Library.

Bhamra, T., \& Lofthouse, V. (2007). Design for sustainability: A practical approach. Aldershot: Gower.

Brezet, H. (1997). Dynamics in ecodesign practice. UNEP IE: Industry and Environment, 20(1-2), 21-24.

Cholette, S., \& Roeder, T. (2012). Embedding a sustainability module into quantitative business courses. INFORMS Transactions in Education, 13(1), 44-56.

ECO2. (1994). Workshop: defining Ecodesign. In Environmentally \& Economically Sensitive Design (ECO 2), Forum 2. Report.

Elkington, J. (1997). Cannibals with forks: The triple bottom line of 21st century business. Oxford: Capstone Publishing Ltd.

Escobar-Tello, M.C., (2016). A design framework to build sustainable societies: using happiness as leverage. The Design Journal, 19 (1), pp.93-115

Friedman, T. L. (2005). Global is good. The Guardian. Newspaper Article, London.

Gander, P. (2007). Refill and reuse to reduce costs. Packaging News. Retrieved from http://www.packagingnews.co.uk/news/736175/Refill-reuse-reduce-costs/

Gittleson, K. (2013). Ten things you didn’t know about Black Friday. BBC. Retrieved from http://www.bbc.co.uk/news/business-25110953

Herman Miller. (2005). Environmental product Summary - Mirra chair. Electronic source. Retrieved from http://www.hermanmiller.com

Humphries-Smith, T. (2007). Sustainability in the curriculum) that is the question - and do we have a choice ? (September), 1-6.

Koninklijke Philips Electronics N.V. (2002). Philips environmental improvement programme. Retrieved from http://www.philips.com/InformationCenter/Global/FArticleSummary.asp?1NodeId=663\&channel=663\&ch annelId=N663A1902

Koninklijke Philips Electronics N.V. (2016). Our green products. Retrieved from http://www.philips.com/aw/about/sustainability/sustainable-planet/green-products-and-green-innovation.html

Lilley, D. (2009). Design for sustainable behaviour: Strategies and perceptions. Design Studies, 30(6), 704-720.

Lilley, D., \& Lofthouse, V. (2009). Sustainable design education - Considering design for behavioural change. Engineering Education: Journal of the Higher Education Academy Engineering Subject Centre, 4(1), 2941.

Lofthouse, V. A. (2001a). Facilitating ecodesign in an industrial design context: An exploratory study (PhD Thesis). Cranfield University, Cranfield.

Lofthouse, V. A. (2001b). Information/inspiration. Retrieved from www.informationinspiration.org.uk

Lofthouse, V. (2004). Investigation into the role of core industrial designers in ecodesign projects. Design Studies, 25(2), 215-227. Retrieved from http://doi.org/10.1016/j.destud.2003.10.007

Lofthouse, V. A. (2006). Ecodesign tools for designers: Defining the requirements. Journal of Cleaner Production, 14(15-16), 1386-1395.

Lofthouse, V. A. (2007). A creative approach to investigating refillable packaging systems. Proceedings from CIWM 2007. Torquay.

Lofthouse, V. (2013). Social issues: Making them relevant and appropriate to undergraduate student designers. Design and Technology Education: An International Journal, 18(2), 8-23. Retrieved from http://ojs.lboro.ac.uk/ojs/index.php/DATE/article/view/1836

Lofthouse, V. A., Bhamra, T. A., \& Trimingham, R. L. (2003). Packaging technology and science. Retrieved from http://www3.interscience.wiley.com/cgi-bin/jhome/4545

Lofthouse, V., \& Bhamra, T. (2000). Ecodesign web. Cranfield University.

Lofthouse, V., Manley, A., \& Shayler, M. (2015). Carbon footprinting for design education. In R. Vande Zande, 
E. Bohemia, \& I. Digranes (Eds.), Learn X Design The 3rd International Conference for Design Education Researchers (pp. 774-789). Chicago, Illinois.

Lofthouse, V., \& Stevenson, N. (2013). Is the industrial designer's changing role improving their opportunities for responsible design practices? In IASDR13 International Association of Societies of Design Research. Tokyo.

Luttropp, C., \& Lagerstedt, J. (2006). EcoDesign and the ten golden rules: Generic advice for merging environmental aspects into product development. Journal of Cleaner Production, 14(15-16), 1396-1408. Retrieved from http://doi.org/10.1016/j.jclepro.2005.11.022

Macdonald-Smith, C. S., \& Short, T. D. (2007). Design for sustainability: The DFS matrix. In S. Rahimifard (Ed.), 5th International Conference on Design and Manufacture for Sustainable Development. Loughborough, UK.

Miles, M. B., \& Huberman, A. M. (1994). An expanded sourcebook-Qualitative data analysis (2nd ed.). London, UK: Sage Publications.

Nussbaum, B. (2007). Are designers the enemy of design? Business Week. Retrieved from http://www.businessweek.com/innovate/nussbaumondesign/archives/2007/03/are_designers_t.html

Papanek, V. (1971). Design for the real world: Human ecology and social change. New York, NY: Pantheon Books.

Perez, V. M. (2016). Facilitating sustainability of a product's lifecycle impact in the early stages of product development (Doctoral thesis). Northumbria University.

Philips Design. (2015). Senseo Up coffee maker. Retrieved from https://www.90yearsofdesign.philips.com/article/6

PRé Consultants. (2000). Eco-indicator 99 manual for designers. The Hague.

PRé Consultants. (1999). Eco-indicator 99. Retrieved from http://www.pre.nl/eco-indicator99/ecoindicator_99 introduction.htm

Red Dott Award: Product. (2015). Red Dott Award: Adjudication criteria. Retrieved from http://reddot.de/pd/jury-2015/adjudication-criteria/?lang=en

Schon, D. (1990). Educating the reflective practitioner. Oxford: Jossey-Bass.

Sherwin, C. (2004). Design and sustainability. The Journal of Sustainable Product Design, 4(1-4), 21-31. Retrieved from http://doi.org/10.1007/s10970-006-0003-x

Sherwin, C. (2012). Embedding sustainability in all design. Retrieved from www.theguardian.com/sustainablebusiness/blog/embedding-sustainability-design-future

Short, T., Lee-Mortimer, A., Luttropp, C., \& Johansson, G. (2012). Manufacturing, sustainability, ecodesign and risk: Lessons learned from a study of Swedish and English companies. Journal of Cleaner Production, 37, $342-352$

Simon, M., Evans, S., McAloone, T., Sweatman, A., Bhamra, T., \& Poole, S. (1998). Ecodesign navigator - A key resource in the drive towards environmentally efficient product design. Manchester Metropolitan, Cranfield University, EPSRC. ISBN-1871315-74-3

Stevenson, N. (2013). A better world by design? An investigation into industrial design consultants undertaking responsible design within their commercial remits. Loughborough University.

Stevenson, N., Lilley, D., Lofthouse, V. A., \& Cheyne, A. (2011). The complexity of responsible design: Key factors affecting industrial design consultants addressing the greater needs of society. In Sustainable Innovation 11: "State of the Art" in Sustainable Innovation and Design, 16th International Conference (pp. 178-188). Farnham, Surrey.

The Creators Project. (2013). Make it wearable finalists | Meet Team BabyBe [Video file]. Retrieved from https://www.youtube.com/watch?v=O4gR9DyFe_0\&feature=player_embedded

University of Cambridge. (2008). CES EducPack. Cambridge: Granta Design Limited.

Wilson, G. T., Bridgens, B., Hobson, K., Lee, J., Lilley, D., Scott, J. \& Suckling, J. (2015). “Single product, multi-lifetime components: challenges for Product-Service System development. In Product Lifetimes and the Environment (PLATE), Nottingham Trent University. 
Vicky Lofthouse Preparing the way for mainstream sustainable product design

WRAP. (2015). Estimates of food and packaging waste in the UK grocery retail and hospitality supply chains. Retrieved from http://www.wrap.org.uk/sites/files/wrap/UK Estimates February 15 (FINAL).pdf 